\title{
O PORTO DE ROTERDÃ E PROJETOS SUSTENTÁVEIS
}

\author{
Amanda Spada Ferreira \\ FATEC-INDAIATUBA - CEETEPS, amanda.ferreira21@fatec.sp.gov.br \\ Any Leslie Vilela Machado Mundim \\ FATEC-INDAIATUBA - CEETEPS, any.mundim@fatec.sp.gov.br \\ Barbara Regina Lopes Costa \\ FATEC-INDAIATUBA - CEETEPS, babhy@terra.com.br \\ Gabriele Oller de Oliveira \\ FATEC-INDAIATUBA - CEETEPS, gabriele.oliveira5@fatec.sp.gov.br \\ Taíza da Costa \\ FATEC-INDAIATUBA - CEETEPS, taiza.costa@fatec.sp.gov.br
}

\begin{abstract}
RESUMO
A relação porto marítimo e meio ambiente é extremamente complexa, o que tem levado os portos a buscarem novos conceitos de gestão e novas práticas portuárias sustentáveis. Este artigo é o resultado de uma pesquisa que teve por objetivo compreender a relação de projetos sustentáveis com as movimentações do Porto de Roterdã, localizado ao sul dos Países Baixos. Para isso, adotou-se como metodologia um estudo qualitativo de caráter exploratório e, através de análise documental, observou-se que a sustentabilidade no Porto de Roterdã garante maior responsabilidade e segurança nas esferas ambientais e sociais, uma vez que a inovação desses projetos no ramo portuário ameniza os danos à vida aquática e terrestre. Como resultado, há uma diminuição dos impactos das atividades portuárias no meio ambiente e o Porto de Roterdã passa a ser um diferencial nas operações de Comércio Exterior.
\end{abstract}

PALAVRAS-CHAVE: Porto de Roterdã. Projetos. Sustentabilidade.

\begin{abstract}
The relationship between sea port and the environment is extremely complex, which has led ports to seek new management concepts and new sustainable port practices. This article is the result of research that aimed to understand the relationship of sustainable projects with the movements of the Port of Rotterdam, located in the south of the Netherlands. To this end, a qualitative study of an exploratory nature was adopted as a methodology and, through documentary analysis, it was observed that sustainability in the Port of Rotterdam guarantees greater responsibility and safety in the environmental and social spheres, since the innovation of these projects in the port branch alleviates damage to aquatic and terrestrial life. As a result, there is a decrease in the impacts of port activities on the environment and the Port of Rotterdam becomes a differential in Foreign Trade operations.
\end{abstract}

Keywords: Port of Rotterdam. Projects. Sustainability. 


\section{INTRODUÇÃO}

Desde a antiguidade os portos são importantes para o comércio e o desenvolvimento da economia, pois é através da cadeia logística marítima que se viabiliza trocas de mercadorias e passageiros entre as sociedades (CHAN, 2016). Os ancoradouros são o principal modal logístico utilizado para o transporte de mercadorias no comércio internacional, unindo os mais distantes países (SOARES, 2009). Instituições que têm demonstrado sua durabilidade por séculos, como o Porto de Roterdã, considerado o maior da Europa, existe desde o século 14, quando ainda era um pequeno porto para pesca, situado no rio Rotte. O Porto de Roterdã tem contribuído com a distribuição e abastecimento de carga para toda a Europa e outros continentes, além disso, é conhecido pela luta para se tornar um dos portos mais sustentáveis (BRAGA, 2020), visando prezar pela preservação do meio ambiente e manter uma relação saudável entre o trinômio: porto, sociedade e natureza.

A complexidade dos impactos ambientais gerados pela atividade portuária tem sido motivo de preocupação em vários países (SOARES, 2009), se por um lado a atividade portuária desempenha um papel no desenvolvimento econômico e social ao gerar empregos, promover o crescimento das cidades, fomentar culturas, ser, também, espaço de lazer, por outro afeta a estabilidade dos ciclos ecológicos, trazendo consequências para a saúde humana, biota e qualidade dos recursos naturais (CHAN, 2016).

Legislações nacionais e internacionais foram criadas para portos novos e existentes, englobando questões sustentáveis e criando normas rigorosas destinadas ao desenvolvimento de projetos que minimizem os impactos ambientais nas operações dos portos (MERLIN; GONÇALVES, 2018). Diante disso, se indaga: de que forma projetos sustentáveis podem refletir nas movimentações do Porto de Roterdã?

Assim, esse estudo busca compreender como medidas sustentáveis impactam a logística, a economia e negociações de um porto e averiguar quais medidas foram adotadas. Também investiga informações que evidenciam as vantagens de adotar a sustentabilidade nas atividades portuárias.

Dada à extensão do assunto, este projeto de pesquisa delimitou-se em colher informações e salientar os impactos de projetos sustentáveis na movimentação do Porto de Roterdã, nos Países Baixos. 


\section{EMBASAMENTO TEÓRICO}

\subsection{Atividades Portuárias e os Impactos Ambientais}

Os portos são instalações construídas à beira de oceanos, mares, rios ou lagos. Essas instalações servem para atracação e abrigo de barcos e navios, que movimentam cargas e pessoas por todo o mundo (BRAGA, 2020). Na história mundial, foram as navegações que permitiram o desenvolvimento e colonização dos países, logo os portos foram essenciais para o processo de globalização que se conhece hoje.

Assim, países e empresas passaram a entrar em mercados internacionais; quem tem capacidade para produzir exporta e quem tem necessidade e não produz importa, beneficiando todos e alavancando a economia global (BOLDORINI, 2017). Visto que a maior parte das mercadorias negociadas é transportada pelo modal marítimo, o porto é peça fundamental para que isso aconteça.

A não implantação de um porto resulta em privações de oportunidades sociais e econômicas para o país e cidades de sua influência (CHAN, 2016), no entanto, por mais que seus benefícios para a economia sejam incontestáveis, as atividades portuárias resultam em impactos ambientais que extrapolam a mera área geográfica do porto (BRAGA, 2020), essas atividades e suas operações trazem consequências não somente para o espaço ao redor como para as gerações vigentes e futuras, próximas ou distantes do porto. Pereira et al. (2016) afirma que é impossível um porto existir sem nenhuma interferência no meio ambiente e são vários os possíveis impactos ambientais decorrentes das atividades portuárias, seja na operação ou nos empreendimentos realizados no sistema portuário. Em construções, reformas, dragagens, aterros ou na própria atividade portuária, impactos resultantes podem trazer riscos à saúde e à segurança local, além de comprometerem os ecossistemas.

A instalação de um porto requer, por exemplo, o desmate da área costeira, pois é preciso grandes áreas para a construção de píer de atracação dos navios e de armazéns, alterando assim, a dinâmica do mar e a área ao redor da costa (DOMIT, 2020), áreas naturais consideradas muito sensíveis. Há ainda o impacto na vegetação, muitas vezes de maneira irreversível; há derramamento de óleo no mar por conta da movimentação das embarcações, que contamina as águas e causa o desequilíbrio ecológico das espécies marinhas (JESUS, 2015); e ainda a poluição sonora, a poluição atmosférica e a proliferação de vetores patogênicos, prejudicando drasticamente a saúde humana e animal. 
Citados alguns exemplos dos impactos ambientais resultantes das atividades portuárias, nota-se que a relação porto e meio ambiente é extremamente complexa, o que tem levado os portos a buscarem novas práticas e novos conceitos de gestão portuária sustentável (JESUS, 2015), de maneira que haja um equilíbrio sustentável tanto para os portos, quanto para o meio ambiente.

\subsection{O Porto de Roterdã}

Na metade do século XIII, Roterdã era ainda uma vila de pescadores e teve seus direitos municipais reconhecidos somente em 1328. Foi nesse mesmo ano que se deu o início à construção do 'velho porto', que seguiu se desenvolvendo gradualmente (PORT OF ROTTERDAM, 2021).

Entre 1600 e 1620 os primeiros ancoradouros foram construídos e a área ao redor começou a ser preenchida. Armazéns, estaleiros, cervejarias, destilarias e refinarias foram surgindo. Com o comércio e o setor de embarcações crescendo, os séculos XVII e XVIII foram considerados os séculos de 'ouro' para o desenvolvimento da cidade e, consequentemente, de seu porto (PEREIRA, 2003), marcando assim o começo da expansão do Porto de Roterdã.

Hoje, a cidade de Roterdã se destaca na Europa, pelo melhor clima de investimento, em razão de seu porto marítimo, do aeroporto, da infraestrutura de alta qualidade e das conexões com o resto do mundo (PORT OF ROTTERDAM, 2021) contribuindo para que os Países Baixos sejam considerados a sexta maior potência econômica da Europa e o quinto maior exportador de mercadorias.

O país emprega $2 \%$ da população no setor agrícola, $16 \%$ em atividade industrial e o maior percentual - $82 \%$ - está no setor de serviços, que inclui transportes, distribuição, logística, bancos e seguros, engenharia hidráulica e novas tecnologias (SANTANDER, 2021), sendo o grande responsável por esse número, o Porto de Roterdã.

Com quase oito séculos de existência, o Porto de Roterdã passou por várias expansões, foi bombardeado e arrasado durante a $2^{\circ}$ Guerra Mundial e ao longo dos anos foi reconstruído com estruturas mais eficientes e inovadoras (PEREIRA, 2003). Atualmente é o 10 maior porto marítimo do mundo, criando empregos diretos e indiretos para cerca de 385.000 pessoas (PORT OF ROTTERDAM, 2021).

Controlado pela Administração Municipal desde 1932, o Porto de Roterdã tornou-se em 2004 uma empresa privada. Seus diretores passaram a ser eleitos através de um conselho 
formado por representantes da comunidade, das empresas, de entidades ambientalistas e do governo (SILVA et al., 2012), garantindo ampla autonomia dos administradores, uma vez que as autoridades públicas não interferem em suas atividades, o que contribui para maior rapidez na tomada de decisões.

Com uma extensão de 42 quilômetros e mais de $100 \mathrm{~km}^{2}$ é o maior porto de contêineres da Europa, seus terminais estão entre os mais modernos do mundo e devido a sua grande profundidade e sem restrições de marés ou bloqueios, os maiores navios portacontêineres (mais de 24.000 TEU) podem chegar aos terminais 24 horas por dia, sete dias por semana (PORT OF ROTTERDAM, 2021), sendo um porto que nunca dorme.

Considerado a principal porta de entrada para um mercado de mais de 350 milhões de consumidores apenas na Europa, o Porto de Roterdã movimenta em torno de 469 milhões de toneladas de carga por ano (PORTO CENTRAL, 2021) e a grande maioria das mercadorias é transportada por contêineres.

Após receber os maiores navios do mundo, as mercadorias - seja a granel ou em contêineres - são transferidas para navios menores, que abastecem outras partes da Europa e do mundo (COELHO, 2011) ou ainda são levadas por trilhos ou estradas para o interior europeu, visto que o porto de Roterdã tem mais de 400 conexões ferroviárias internacionais e está diretamente conectado à rede de rodovias nacionais e europeias (PORT OF ROTTERDAM, 2021), facilitando tanto a chegada como a saída de mercadorias do porto.

\section{METODOLOGIA}

Para obter os resultados e respostas acerca da problematização apresentada neste trabalho, foi feita uma análise do Porto de Roterdã no contexto geral e todos os impactos que a atividade portuária exerce ao meio ambiente, através da pesquisa exploratória de caráter qualitativo (GERHARDT; SILVEIRA, 2009).

O Porto de Roterdã foi escolhido por ser considerado o mais sustentável do mundo e ainda implantar projetos inovadores em suas atividades. Deste modo, pode-se desfrutar de diversos conhecimentos e analise de pontos de vista de estudiosos dedicados a essa temática. Para tal, foi utilizado o método de pesquisa bibliográfica e documental que tem como finalidade colocar o pesquisador em contato direto com tudo o que foi escrito, dito ou filmado sobre determinado assunto (GERHARDT; SILVEIRA, 2009). Assim, foram selecionados e 
estudados materiais já publicados referente ao Porto, como trabalhos acadêmicos, artigos, sites, etc.

\section{ANALISE E DISCUSSÃO DOS RESULTADOS}

A preocupação em relação à degradação ambiental nos diversos meios tem gerado muitas cobranças sobre sustentabilidade, inclusive nas atividades portuárias, classificadas como altamente poluidoras (PEREIRA et al., 2016), então para se tornar mais competitivo, o sistema portuário deve adequar-se ao novo padrão mundial, cumprindo normas e padrões internacionais de qualidade, sustentabilidade económica e social, bem como de preservação do meio ambiente (BRAGA, 2020).

O Porto de Roterdã é considerado um dos portos mais sustentáveis do mundo e afirma estar empenhado cada vez mais em realizar mudanças significativas no que se refere ao meio ambiente. Seu objetivo é combater as mudanças climáticas e, ao mesmo tempo, garantir que o porto e seus arredores sejam seguros, saudáveis e atraentes (PORT OF ROTTERDAM, 2021) resultando numa contribuição significativa para a comunidade holandesa e para o mundo.

Com projetos ambiciosos, o Porto de Roterdã envolve partes interessadas dentro do seu complexo industrial e também empresas ao seu redor para colaborar com os desafios encontrados. As empresas interessadas em se instalar na nova área do porto, o Maasvlakte 2 - projeto de expansão que estabelece uma nova área portuária e industrial, por exemplo, devem atender exigências rígidas em termos de sustentabilidade, incluindo qualidade do ar, ruído, transporte, uso de energia, resíduos, etc., todas elas estabelecidas pela Autoridade Portuária de Roterdã (PORT OF ROTTERDAM, 2021)

O acordo de Paris sobre mudança climática é uma das mudanças legislativas mais recentes que motivam o porto a reduzir as emissões de $\mathrm{CO}^{2}$, então visando soluções limpas e de baixa emissão de gás carbono, mudou seu foco para combustíveis e outras soluções mais sustentáveis (BRAGA, 2020). Com o lema "Renovar o existente e abraçar o novo para alcançar um Porto Neutro líquido de $\mathrm{CO}^{2}$ em 2050", foi criado um programa de transição energética (PORT OF ROTTERDAM, 2021), dividido em 3 etapas: eficiência e infraestrutura; transição para um novo sistema de energia; e um novo sistema de matérias-primas e combustível. Cada uma dessas etapas, com as suas características e objetivos agrupam subgrupos de projetos, que embora já sejam muitos, não param de ampliar-se. Os projetos contidos nesses subgrupos ao 
serem desenvolvidos auxiliam no atingimento do objetivo de cada etapa, contribuindo para a transição energética.

A primeira etapa do programa envolve ações empresariais com medidas inteligentes de eficiência, focadas na sustentabilidade. O Gasoduto Gotlek, é um projeto exemplo dessas ações; a criação da rede conecta indústrias, que produzem vapor por meio de seus processos de negócio e distribuem para outras empresas próximas, que precisam desse vapor, evitando a liberação do vapor na atmosfera. Essa infraestrutura resulta em uma redução anual das emissões de $\mathrm{CO}^{2}$ de cerca de 400.000 toneladas (PORT OF ROTTERDAM, 2021).

Na segunda etapa há projetos que visam mudar o sistema de energia, em vez de usar petróleo e gás para aquecimento, a indústria mudará para energias de baixo nível poluente ou nenhum, como sol e vento, já que a utilização de fontes de energia não renováveis e que são facilmente esgotáveis, causam inúmeros problemas ambientais (TODA MATÉRIA, 2021). Dentre os diversos projetos, foi implantado, o sistema de energia solar nos telhados dos armazéns frigoríficos, que consomem $2,7 \mathrm{Kw} / \mathrm{h}$ anualmente. Desta maneira, o sistema cobre 28\% da demanda energética (SUSTENTARQUI, 2016) e contribui para a redução de CO² $^{2}$ Já o projeto $\mathrm{H}$-Vision pretende fornecer à indústria energia de baixo $\mathrm{CO}^{2}$ antes de 2030, substituindo o gás natural por hidrogênio azul e possivelmente também usando gases residuais.

A última etapa do programa contorna projetos para a substituição de combustíveis fósseis, feito através do uso de biomassa, materiais reciclados, hidrogênio verde e $\mathrm{CO}^{2}$. O W2C - Waste to Chemicals tido como modelo, é um projeto único na Europa, do Porto de Roterdã em conjunto com a Air Liquide, Enerkem, Nouryon e a Shell, que converte resíduos plásticos e outros resíduos mistos em novas matérias-primas (PORT OF ROTTERDAM, 2021), evitando também a queima de resíduos e o uso de fontes fósseis para novos materiais.

Além da indústria, a cidade de Roterdã também trabalha para estimular o transporte marítimo a usar combustíveis alternativos, e em parceria com a Neste, maior produtora mundial de diesel renovável, o Porto teve um investimento de 1,5 bilhão de euros, para construir uma usina e dobrar a capacidade de produção de combustíveis renováveis e matérias-primas. Essa construção implicará em mais de 100 empregos, pode economizar aproximadamente 3,5 milhões de toneladas de emissões de carbono por ano (PORT OF ROTTERDAM, 2021) e dará um impulso importante à transição energética. 
A região do Porto de Roterdã já abriga uma série de projetos onde todos os tipos de empresas trabalham juntas. O Green carpet to the future, é um projeto lançado para empreendedores com ideias sustentáveis, ele analisa e implementa os melhores e mais promissores projetos ao porto ou empresa parceria; o Think Bige expõe ideias de outras empresas que também cooperam com nova economia e colaboram junto ao porto para um futuro mais sustentável (PORT OF ROTTERDAM, 2021), garantindo que, além de um futuro sustentável, tenham também um empreendimento de sucesso.

Preocupado em oferecer eficiência e competitividade para seus parceiros, o Porto de Roterdã garantiu, junto com as entidades públicas e privadas, uma extensa rede de transporte intermodal, incluindo acesso marítimo, fluvial, rodoviário, ferroviário e de gasodutos (CHAN, 2016) e criou iniciativas que contribuem para a otimização da cadeia de todos os modos de transporte. Aconselhando e orientando para que ocorram mudanças e que os modais sejam mais sustentáveis, espera-se assim que a cadeia obtenha maior eficiência em seu processo de logística.

Em agosto de 2020, o Porto de Roterdã renovou o seu Sistema de Revisão Ambiental Portuária (PERS), única norma de gestão ambiental específica do setor portuário. Essa certificação exige, entre outros, maior transparência, tornando seu relatório ambiental disponível ao público (BRAGA, 2020). Dessa maneira, o Porto prova que a transparência e o monitoramento do desempenho ambiental são ferramentas importantes do seu compromisso ambiental.

\section{CONSIDERAÇÕES FINAIS}

Com a elaboração desse estudo, foi possível constatar que o Porto de Roterdã possui um diferencial em relação a outras corporações portuárias. É notório que os projetos sustentáveis têm impacto positivo em suas movimentações, uma vez que os investimentos em sustentabilidade resultam em menores impactos da operação portuária no meio ambiente e promovem o reconhecimento por sua responsabilidade, eficiência e inteligência, ao mesmo tempo que gera oportunidades de emprego e colabora com a economia.

Evidencia-se que a sustentabilidade integrada garante maior fluidez no transporte de cargas do Porto de Roterdã, já que outras corporações empresariais, também sustentáveis, dão preferência ao Porto pela sua capacidade de desenvolvimento econômico unido à 
melhoria do ambiente de vida. Além disso, o empenho dessa corporação em tornar-se sustentável pode refletir como incentivo a outras empresas para desenvolver novos projetos, fazendo com que não sejam mais vistos como uma medida opcional, mas necessária.

Valendo-se das informações contidas neste artigo, é justificável o reconhecimento do Porto de Roterdã como um dos portos mais sustentáveis do mundo, assim como sua influência para tal temática, visto que os projetos apresentados demonstram que o Porto tem a preocupação em relação à sustentabilidade além do estabelecido por normas e acordos existentes.

Deste modo, o presente artigo poderá servir como base para estudos futuros, tais como os que buscam analisar e compreender a relação entre o Porto de Roterdã e os demais portos do mundo que investem incisivamente em projetos sustentáveis e os benefícios que proporcionam para os modais de transporte e ao Comércio Exterior.

\section{REFERÊNCIAS}

BOLDORINI, Patrícia Souza Amaral Tardivo. Percepção dos Agentes de Carga em relação às Operações Portuárias de Contêiner: Um Comparativo entre os Portos de Santos, Rotterdam e Xangai. 2017. 91 f. Dissertação (Mestrado) - Curso de Administração, Faculdade de Ciências Empresariais da Universidade Fumec, Belo Horizonte, 2017. Disponível em: https://repositorio.fumec.br/xmlui/handle/123456789/464. Acesso em: 25 mar. 2021.

BRAGA, Rafael Costa Morgado Soares. Gestão Ambiental em Portos Brasileiros: Contributos para melhoria considerando boas práticas em Port. 2020. $196 \mathrm{f}$. Tese (Doutorado) - Curso de Engenharia do Ambiente, Faculdade de Engenharia da Universidade do Porto, Porto, Portugal, 2020. Disponível em: https://hdl.handle.net/10216/131572. Acesso em: 26 fev. 2021.

CHAN, Jessica Saúde. A coexistência de um Porto Sustentável e a Cidade: Caso do Porto de Roterdã na Holanda. 2016. 81 f. Monografia (Especialização) - Curso de Direito Ambiental, Economia Rural e Extensão, Universidade Federal do Paraná, Curitiba, 2016. Disponível em: https://acervodigital.ufpr.br/handle/1884/52284. Acesso em: 25 fev. 2021.

COELHO, Leandro Callegari. Porto de Roterdã. 2011. Logística Descomplicada. Disponível em: https://www.logisticadescomplicada.com/porto-de-roterda/. Acesso em: 10 mar. 2021.

DOMIT, Camila. O impacto de um porto. 2020. Disponível em:

https://www.justicaeco.com.br/o-impacto-de-um-porto-2/?format=pdf. Acesso em: 20 mar. 2021. 
GERHARDT, Tatiana Engel; SILVEIRA, Denise Tolfo (org.). Métodos de Pesquisa. Porto Alegre: Ufrgs, 2009. 120 p. (Educação a Distância). Disponível em:

http://www.ufrgs.br/cursopgdr/downloadsSerie/derad005.pdf. Acesso em: 25 mar. 2021.

JESUS, Rosane Doria de. Porto e Meio Ambiente: um estudo bibliográfico sobre os principais impactos ambientais produzidos pela atividade portuária. 2015. $19 \mathrm{f}$. Monografia (Especialização) - Curso de Gestão Ambiental Portuária, Universidade Santa Cecília, Santos, 2015. Disponível em:

https://periodicos.unisanta.br/index.php/bio/article/download/1959/1483. Acesso em: 25 mar. 2021.

MERLIN, Bruno; GONÇALVES, Adilson Luiz. Padrões de qualidade e desempenho regulam atividades em portos e auxiliam a busca por eficiência. 2018. Disponível em:

https://portogente.com.br/noticias/meio-ambiente/99378-utilizacao-racional-de-recursosnaturais-e-o-futuro-do-planeta. Acesso em: 04 mar. 2021.

MRE - Ministério das Relações Exteriores. Como Exportar Países Baixos. Coleção: Estudos e Documentos de Comércio Exterior, Série: Como Exportar, Brasília, 2002. Disponível em: https://www.fecomerciomg.org.br/wpcontent/uploads/2014/07/como_exportar_paisesbaixos.pdf. Acesso em: 21 fev. 2021.

PEREIRA, Bianca Lima et al. "Greens Ports" e o Porto de Santos. 2016. 47 f. TCC (Graduação) - Curso de Engenharia Civil, Faculdade de Ciências e Tecnologia da Universidade Santa Cecília, Santos, 2016. Disponível em: https://cursos.unisanta.br/civil/GREEN-PORTS.asp. Acesso em: 27 mar. 2021.

PEREIRA, Priscila Ramos. O Sistema Portuário e suas implicações no Comércio Exterior Uma comparação entre o Porto de Santos e o Porto de Roterdã. 2003. 69 f. Monografia (Especialização) - Curso de Relações Jurídicas e Sociais, Uniceub - Centro Universitário de Brasília, Brasília, 2003. Cap. 4. Disponível em:

https://repositorio.uniceub.br/jspui/handle/235/9634. Acesso em: 22 mar. 2021.

PORT OF ROTTERDAM. PLAN YOUR CONTAINER TRANSPORT WITH NAVIGATE. 2021.

Disponível em: https://www.portofrotterdam.com/en. Acesso em: 20 mar. 2021.

PORT OF ROTTERDAM. SETTING A NEW GLOBAL STANDARD IN BIOFUELS, CHEMICALS AND WASTE MANAGEMENT. Porto of Rotterdam. Disponível em: https://w2c-rotterdam.com/. Acesso em: 08 abr. 2021.

PORT OF ROTTERDAM. SUSTAINABILITY. 2021. Porto of Rotterdam. Disponível em: https://www.portofrotterdam.com/en/our-port/our-themes/a-sustainableport/sustainability. Acesso em: 15 mar. 2021.

PORT OF ROTTERDAM. The smart port doesn't stop at the city limits. Porto of Rotterdam. 08 abr. 2019. Disponível em: The smart port doesn't stop at the city limits | Port of Rotterdam. Acesso em: em 06 abr. 2021. 
PORTO CENTRAL. Porto de Roterdã (Holanda). 2021. Disponível em:

https://portocentral.com.br/pb/quem-somos/porto-de-roterda/. Acesso em: 15 mar. 2021.

PORTO GENTE. Porto de Rotterdam - Informações Principais. 2016. Portopédia. Disponível em: https://portogente.com.br/portopedia/73392-porto-de-rotterdam-informacoesprincipais. Acesso em: 18 mar. 2021.

SANTANDER Trade Markets. Economia da Holanda. 2021. Disponível em:

https://santandertrade.com/pt/portal/analise-os-mercados/holanda/economia. Acesso em: 20 fev. 2021.

SILVA, Cristiany Mendonça da et al. O Porto de Roterdã: o melhor porto do mundo. O Melhor Porto do Mundo. 2012. Disponível em: http://logisticatecnologos.blogspot.com/p/oporto-de-reterdam.html. Acesso em: 18 mar. 2021.

SILVA, Nathália Bellio da. Como iniciar o desenvolvimento de um material biodegradável ou de origem sustentável? 2021. Disponível em: https://emejr.com.br/como-iniciar-odesenvolvimento-de-um-material-biodegradavel-ou-de-origem-sustentavel/. Acesso em: 28 fev. 2021.

SOARES, Carlos Roberto. Os portos de Paranaguá (PR) e Itajaí (SC): Análise comparativa das suas relações com as cidades de inserção, da estrutura operacional atual e das condições sócio-ambientais das regiões de entorno. 2009. $184 \mathrm{f}$. Tese (Doutorado) - Curso de Meio Ambiente e Desenvolvimento, Universidade Federal do Paraná, Curitiba, 2009. Disponível em: https://acervodigital.ufpr.br/handle/1884/21093. Acesso em: 25 fev. 2021.

SUSTENTARQUI. Maior porto da Europa recebe energia solar. Disponível em: https://sustentarqui.com.br/maior-porto-da-europa-energia-solar/. Acesso em: 08 abr. 2021.

TODA MATÉRIA. Energia não Renovável. Toda Matéria. Disponível em: https://www.todamateria.com.br/energia-nao-renovavel/. Acesso em: 05 abr. 2021.

"Os autores declaram estar cientes quanto a responsabilidade pelo conteúdo do artigo." 